\title{
STOICHIOMETRY AND INTERDIFFUSION IN PZT THIN FILMS STUDIED BY TRANSMISSION ELECTRON MICROSCOPY
}

\author{
L. SAGALOWICZ, P. MURALT, S. HIBOUX, T. MAEDER, K. BROOKS, Z. KIGHELMAN \\ AND N. SETTER \\ Ceramics Laboratory, Materials Department, EPFL Swiss Federal Institute of Technology, CH- \\ 1015-Lausanne.
}

\begin{abstract}
Electrode stability, interdiffusion, phase purity and deviation from stoichiometry at the PZT-electrode interface are key issues in PZT thin film integration. This article highlights the use of transmission electron imaging combined with energy dispersive spectroscopy (EDS) for the investigation of these phenomena. The accuracy of the EDS analysis is discussed. It will be shown that using a standard PZT sample and controlled conditions, reliable analysis can be performed.

Diffusion mechanisms have been studied for Pt based electrode systems and $\mathrm{RuO}_{2}$-based electrode systems developed for direct integration onto silicon. The materials studied were composed of stacks of silicon-silicon oxide, an adhesion layer $\left(\mathrm{Ti}, \mathrm{Ta}\right.$ or $\left.\mathrm{TiO}_{\mathrm{x}}\right)$, an electrode $(\mathrm{Pt}$ or $\mathrm{RuO}_{2}$ ) and PZT (45/55). The PZT was deposited by sol gel using the same parameters to allow for comparison of the different electrodes. Four different electrode / adhesion layer materials were compared ( $\mathrm{Pt} / \mathrm{Ti}, \mathrm{Pt} / \mathrm{TiO} \mathrm{x}, \mathrm{Pt} / \mathrm{Ta}$ and $\mathrm{RuO}_{2} / \mathrm{TiO}_{2}$ ). In the case of Pt, lead and oxygen diffusion through the electrode is observed. While the initial Ta layer transforms into a homogeneous pyrochlore phase, the $\mathrm{Ti}$ adhesion layer is heavily deformed. In the case of $\mathrm{TiO}_{\mathrm{x}}$ the lead is mainly incorporated at the interfaces with $\mathrm{Pt}$ and with $\mathrm{SiO}_{2}$. No lead diffusion to the adhesion layer is observed for the $\mathrm{RuO}_{2}$ electrode. In-situ sputtering and sol-gel deposition of PZT are also compared. The sol-gel films are close to the right stoichiometry for the perovskite while the sputtered films contained an excess of lead. No sign of second phase is found by X-ray diffraction (XRD), by EDS and by high resolution transmission electron microscopy (HRTEM) which suggests that the excess lead is accommodated in the perovskite lattice.
\end{abstract}

\section{INTRODUCTION}

$\mathrm{Pb}(\mathrm{Zr}, \mathrm{Ti}) \mathrm{O}_{3}$ (PZT) thin films are used for their ferroelectric, piezoelectric and pyroelectric properties. It is often difficult to control the stoichiometry of the PZT. In addition, to obtain good crystallinity, a final annealing around $650^{\circ} \mathrm{C}$ is needed. This high temperature is often associated with volatilization of the lead and with interdiffusion between the PZT and the electrodes. ${ }^{1.2}$ This may affect the mechanical stability of the device and may result in the presence of defects in the active layer. ${ }^{3,4}$

It is of interest to find methods to characterize the stoichiometry of the PZT and to determine if diffusion between the layers occurs. The easiest methods to determine the stoichiometry of the PZT are Rutherford Back Scattering (RBS) and microprobe analysis. Unfortunately, they just give an average of the composition. EDS analysis of a transmission electron microscope (TEM) sample is local but it is often described as being unreliable since lead evaporation and redeposition may take place during TEM sample preparation and observation. ${ }^{1}$ For the active materials, stoichiometry is important since change of stoichiometry may lead to a change in the electrical properties and the appearance of second phases. 
It is also of prime interest to know if diffusion between the layers occurs since it can lead to delamination or change in stoichiometry. This may lead to the formation of secondary phases, and consequently, altered properties. The diffusion behavior depends on the electrode materials. For example, a comparison between $\mathrm{Pt}$ and $\mathrm{IrO}_{2}$ electrodes showed that the oxidized electrode IrO $\mathrm{I}_{2}$ is a better diffusion barrier than $\mathrm{Pt}^{5}$. $\mathrm{RuO}_{2}$ was shown to be a good diffusion barrier as well. 6

The aim of the present study is twofold. Firstly, to describe how reliable EDX measurements can be made. Secondly, to compare different electrodes: $\mathrm{Pt} / \mathrm{Ti}, \mathrm{TiO}_{2} / \mathrm{Pt} / \mathrm{TiO}_{\mathrm{x}}$, $\mathrm{TiO}_{2} / \mathrm{Pt} / \mathrm{Ta}, \mathrm{RuO}_{2} / \mathrm{TiO}_{2}$ and $\mathrm{TiO}_{2} / \mathrm{RUO}_{2} / \mathrm{TiO}_{2}$, and to show how diffusion and stoichiometry can affect the microstrucuture.

\section{RESULTS}

\section{Determination of the stoichiometry by EDS}

The quantitative determination by EDS of the composition of the PZT is difficult since at low thicknesses lead loss and lead redeposition can occur and at higher thicknesses absorption cannot be neglected. In addition, the Cliff-Lorimer factors (k) used to determine the composition need to be known accurately. Therefore, a standard sample has to be used. The stoichiometry of the standard sample was the following : $\mathrm{Pb}_{1.02} \mathrm{Zr}_{0.53} \mathrm{Ti}_{0.47} \mathrm{Nb}_{0.02}$ (within $1 \%$ for each element). The parameterless method developed by VanCapellen was also used. ${ }^{7}$ This method does not involve a direct determination of the TEM sample thickness. The method consists in plotting the composition as a function of the net counts of a characteristic line of one element. The content in each element was plotted (Fig.1) as a function of the normalized Ti counts for the K-lines (the Ti count is divided by the time of the analysis and the current density of the electron beam). The slope observed on the experimental curves (Fig.1) corresponds mainly to absorption.

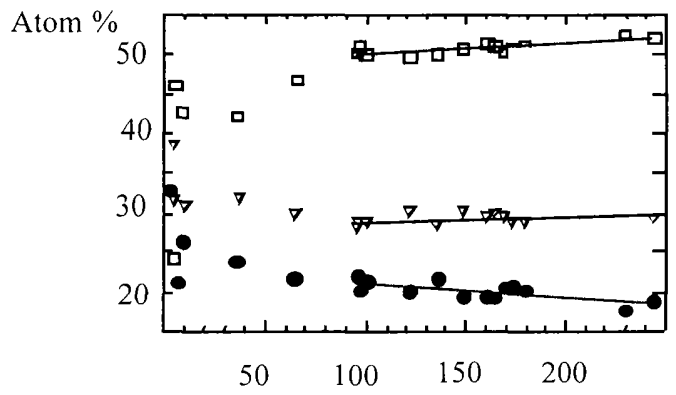

Figure 1 : Atomic content of the PZT. $\mathrm{Pb}$ is represented by open squares, the $\mathrm{Zr}$ is represented by open triangles and $\mathrm{Ti}$ is represented by close circles. Notice that the compositions for $\mathrm{G}$ smaller than 90 are very far from the nominal composition but the values for $\mathrm{G}$ larger than 90 can be used in a reliable way.

$\mathrm{G}$ : Normalized count for the Ti K- lines

It is observed that the composition, corresponding to net counts of a $\mathrm{Ti}$ (representing the thickness) smaller than a given value must be eliminated since large lead losses and lead redepositions have occurred. For large thicknesses, the absorption corrections become important and it is better not to work with those thicknesses. But there is a window of thicknesses for which EDS analysis can be used in a reliable way. The method enables the correction of the Cliff-Lorimer factors $(\mathrm{k})$ used and allows compensation for absorption. More importantly, it 
indicates the best thicknesses to work with (in particular where surface effects are negligible). The measurements are done at liquid nitrogen temperature to avoid excess beam heating.

The uncertainty of the method is estimated to be about $2-3 \%$ on each absolute content when only the metallic species are considered. It was also checked that the method gave correct results when the PZT compounds take the pyrochlore or fluorite structure. For the high thicknesses used, significant variations in lead content could not be detected during successive EDS measurement indicating that lead loss or redeposition is negligible. The lead content determined by our method was always in agreement (within $2 \%$ ) with that determined from microprobe or RBS analysis when the sample was homogeneous enough. The uncertainity on the $\mathrm{Zr}$ :Ti ratio is more difficult to know since this ratio often varies significantly. The microprobe analysis gives an average composition over a large area and the TEM analysis is very localized. The main limitation of the proposed method is that only thick areas can be used losing some spatial resolution associated with the TEM analysis.

\section{Description of the substrates to be compared}

PZT was deposited onto an $\mathrm{SiO}_{2} / \mathrm{Si}$ substrate $\left(\mathrm{SiO}_{2}: 1 \mu \mathrm{m}\right)$ coated with an adhesion layer ( $\mathrm{Ti}, \mathrm{Ta}$ or $\left.\mathrm{TiO}_{\mathrm{x}}\right)$, the electrode material itself $\left(\mathrm{Pt}\right.$ or $\left.\mathrm{RuO}_{2}\right)$, and when necessary a seed layer of $\mathrm{TiO}_{2}$. The electrodes which were compared were : $\operatorname{Pt}(100 \mathrm{~nm}) / \mathrm{Ti}(10 \mathrm{~nm}), \mathrm{TiO}_{2}(2 \mathrm{~nm}) /$ $\mathrm{Pt}(100 \mathrm{~nm}) / \mathrm{Ta}(10 \mathrm{~nm}), \mathrm{TiO}_{2}(2 \mathrm{~nm}) / \mathrm{Pt}(100 \mathrm{~nm}) / \mathrm{TiO}_{\mathrm{x}}(25 \mathrm{~nm})$ and $\mathrm{TiO}_{2}(2 \mathrm{~nm})$ / $\mathrm{RuO}_{2}(100 \mathrm{~nm}) / \mathrm{TiO}_{2}(30 \mathrm{~nm})$. The different layers beneath the PZT were deposited at $400^{\circ} \mathrm{C}$ except the $\mathrm{RuO}_{2}$ which was deposited at $500^{\circ} \mathrm{C}$. A temperature of $400^{\circ} \mathrm{C}$ for the Pt is the maximum for which a (111) orientation can be obtained. The PZT was prepared by a sol-gel route with a final annealing at $650^{\circ} \mathrm{C}$ for $15 \mathrm{~min}$.

\section{Features common to all the films}

The grain structure of the PZT appears to be columnar with an average width of 100$150 \mathrm{~nm}$ (Fig.2) which is in full agreement with the plan view images (Fig.3). No evidence of second phase was found within the PZT by SEM and TEM. EDS analysis reveals that the Pb content was always close (within $2 \%$ which corresponds to the uncertainity of the method) to that of the stochiometric perovskite. The contrast present in the dark field images indicates that some structural defects are present. Those are probably low angle grain boundaries, dislocations and domains. This is partly due to the relatively low temperature of the deposition method.

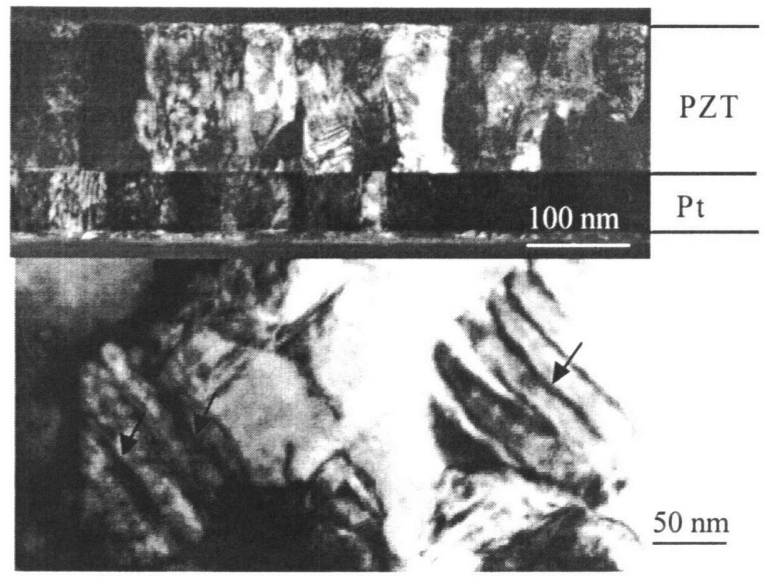

Figure 2 : Dark field cross section TEM image showing the columnar structure of the $45 / 55$ PZT films obtained by sol-gel deposition.

Figure 3 : Dark field plan view image showing the surface of the PZT 45/55 (deposited on $\mathrm{RuO}_{2}$ ). No sign of second phase in the grain interior and in the grain boundaries is present. $90^{\circ}$ domain walls are clearly visible (arrowed). 


\section{Features common to all films deposited onto Pt electrodes}

The Pt electrodes in all cases show a columnar structure with an average grain size of 50$100 \mathrm{~nm}$. XRD demonstrates that the Pt and the PZT films are (111) oriented. For our deposition conditions, it is found that the Pt electrode is not an efficient barrier to diffusion. In all cases, some $\mathrm{Pb}$ and oxygen are detected in the adhesion layer. Defects which have a diameter less than $10 \mathrm{~nm}$ are also present at the interface Pt-PZT (not shown here). The defects often lie on Pt grain boundaries, indicating that they are the result of diffusion with the bottom electrode. Sometimes they appear as porosity within the TEM sample. However, since the fluorite contains more defects (porosity, weaker bonds) than the perovskite, it will disappear first in the TEM-sample preparation and the porosity may correspond to the removal of this fluorite phase. $\mathrm{Pb}$ diffusion to the bottom electrode would prevent the PZT from having the right stoichiometry close to to the interface and the perovskite will not nucleate in this region. The fluorite, which is more tolerant to changes in composition, would be present instead. It is therefore concluded that both porosity and fluorite may be present at the PZT/Pt interface and are likely to result from diffusion between PZT and Pt.

\section{Differences between films obtained for the Pt electrodes using different adhesion layer}

\section{a. Pt $(100 \mathrm{~nm}) / \mathrm{Ti}(10 \mathrm{~nm})$ substrate}

The Ti adhesion layer looks irregular (fig. 4a) because of diffusion. The adhesion layer seems also very porous and the interfaces with the $\mathrm{SiO}_{2}$ and $\mathrm{Pt}$ are not well defined. Precipitates rich in Pt were also found in the adhesion layer, and it was also determined that an important amount of $\mathrm{Pb}$ is present in the $\mathrm{Ti}(\% \mathrm{~Pb} /(\% \mathrm{~Pb}+\% \mathrm{Ti}) \approx 0.15)$ and in the $\mathrm{SiO}_{2}$ close to the adhesion layer. XPS shows that the adhesion layer is oxidized.

\section{b. Pt (100 nm) / Ta $(10 \mathrm{~nm})$ substrate}

The adhesion layer and the Pt appear more regular than in the case of the Ti (Fig.4b). It also appears thicker $(40 \mathrm{~nm}$ instead of about $30 \mathrm{~nm})$ than in the case of the Ti. A large amount of $\mathrm{Pb}$ is present in the adhesion layer but it is uniformly distributed $(\% \mathrm{~Pb} /(\% \mathrm{~Pb}+\% \mathrm{Ta})) \approx 0.3$. The diffusion of $\mathrm{Pb}$ and oxygen corresponds to the stabilization of a TaPbO phase. Peaks corresponding to this compound were found by XRD.

\section{c. Pt (100 nm) / $\mathrm{TiO}_{x}(25 \mathrm{~nm})$ substrate}

In the case of $\mathrm{TiO}_{\mathrm{x}}$ adhesion layer, little deformation (Fig.4c) is observed and the $\mathrm{TiO}_{\mathrm{x}}$ layer is not too much affected by diffusion of other metallic species. However in the Pt-TiO interfaces and in the $\mathrm{SiO}_{2} / \mathrm{TiO}_{\mathrm{x}}$ interfaces, defects are present. EDX analysis reveals that the content of lead is maximum in the $\mathrm{SiO}_{2}$ close to the adhesion layer. An intermediate layer is also present between $\mathrm{TiO}_{\mathrm{x}}$ and $\mathrm{Pt}$. It contains some lead and probably $\mathrm{Ti}$ and $\mathrm{Pt}$. In the middle of the adhesion layer the $\mathrm{Pb}$ content is relatively low : $(\% \mathrm{~Pb} /(\% \mathrm{~Pb}+\% \mathrm{Ti})) \approx .04$. This is the adhesion layer for which the lowest amount of lead diffusion is detected and the observed diffusion may be associated with the fact that the titanium is not completely oxidized since the adhesion on fully oxidized $\mathrm{Ti}$ is insufficient and $\mathrm{Pt}$ orientation is affected as well. The adhesion layer $\mathrm{TiO}_{x}$ is a trade off between adhesion and $\mathrm{Pt}$ orientation on one hand ( $\mathrm{Ti}$ is the best) and chemical stability on the other hand $\left(\mathrm{TiO}_{2}\right.$ is probably the best). 


\section{d. Deposition onto $\mathrm{TiO}_{2}(2 \mathrm{~nm}) / \mathrm{RuO}_{2}(100 \mathrm{~nm}) / \mathrm{TiO}_{2}(25 \mathrm{~nm})$}

The $\mathrm{RuO}_{2}$ is also columnar with a grain width of $40 \mathrm{~nm}$ (not shown here). The interface between $\mathrm{RuO}_{2}$ and PZT is very rough. The $\mathrm{TiO}_{2}$ adhesion layer appears unaffected by the deposition of PZT (Fig.4d) and no $\mathrm{Pb}$ was found in this adhesion layer. The $\mathrm{RuO}_{2}$ appears therefore to be a much better diffusion barrier than Pt.

\section{Deposition by in-situ sputtering at $570^{\circ} \mathrm{C}$ (compared to sol-gel deposition)}

The diffusion behavior between the PZT and the electrode was very similar to what is observed for the sol-gel deposition. However a difference concerns the stoichiometry of the PZT. In sputtering, an excess lead was also used to compensate for $\mathrm{Pb}$ evaporation. EDS and Rutherford back scattering (RBS) analysis demonstrate that the films, which did not show any second phase by XRD, were also rich in lead. This is different from the films deposited by solgel which were close to the perovskite stoichiometry. A film for which the atomic ratio $\mathrm{Pb} /(\mathrm{Zr}+\mathrm{Ti})$ was $58 / 42$ was analyzed by plan view and cross-section TEM. The content of $\mathrm{Pb}$ was very homogeneous. In particular, EDS indicates that there was no excess lead in, or close to, the grain boundaries. No sign of second phase (in the grain interior and in the grain boundary) could be found by XRD and HRTEM (Fig.5). This suggests that the excess lead is incorporated within the perovskite lattice in the $\mathrm{B}$ site as proposed for the case of the perovskite $\mathrm{Pb}\left(\mathrm{Sc}_{1 / 2}\right.$ $\left.\mathrm{Ta}_{1 / 2}\right) \mathrm{O}_{3}$ which was also obtained by in-situ sputtering. ${ }^{8}$
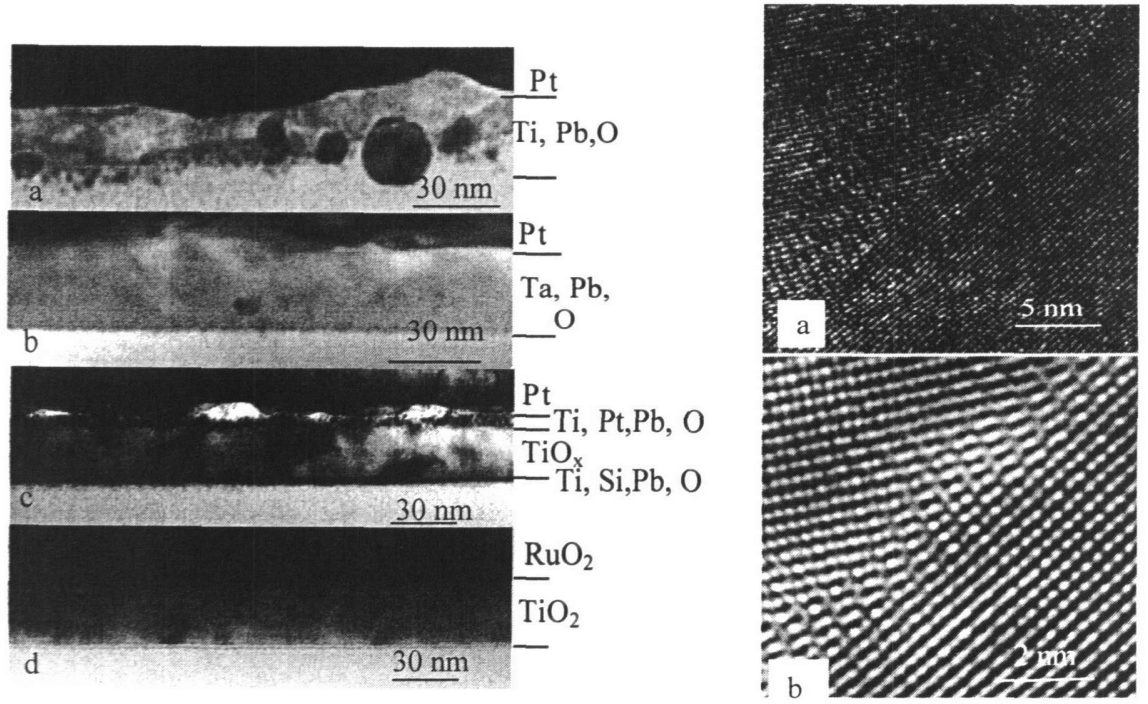

Figure 4 : Bright field images of different adhesion layer-electrode materials. (a) Pt/Ti : lead and oxygen diffusion is obseved in the $\mathrm{Ti}$ (b)Pt/Ta: lead and oxygen diffusion in the $\mathrm{Ta}$ is observed. (c) $\mathrm{Pt} / \mathrm{TiO}_{\mathrm{x}}$ : lead diffusion is observed at the $\mathrm{Pt} / \mathrm{TiO}_{\mathrm{x}}$ and at the $\mathrm{SiO}_{2}-\mathrm{TiO}_{\mathrm{x}}$ interface is observed. (d) $\mathrm{RuO}_{2} / \mathrm{TiO}_{2}$ : no lead diffusion is observed.
Figure 5 : HRTEM images of PZT in a sample containing an excess of lead. (a) normal image, (b) enlarged and filtered image of (a). There is no sign of second phase. The grain at the bottom is [110] oriented and the grain at the top is [211] oriented. 


\section{DISCUSSION}

We discuss here the mechanisms of diffusion. It is first observed that oxidized electrodes and adhesion layer are more stable than the non-oxidized ones. It is therefore believed that the oxidation and reaction with the adhesion layer are important driving forces for diffusion. The cases of Ti and Ta appear different. In the case of $\mathrm{Ti}$, a lot of deformation and diffusion $(\mathrm{Pt}, \mathrm{Pb}$, $\mathrm{Si}$ ) are observed. In the case of $\mathrm{Ta}$, the layer is thicker and much more regular. The difference in behavior might be understood when one knows that in the oxide Ti diffuses more than oxygen while Ta diffuses slower than oxygen. ${ }^{9}$ In a previous study,${ }^{9}$ we showed that when one oxidizes the electrode (without depositing the PZT), almost all the Ti comes to the Pt surface while most of the tantalum stays under the Pt. In the case of $\mathrm{Ti}$, there is upward diffusion of $\mathrm{Ti}$, which leaves a lot of vacancies and voids, which are at least partially filled by downward diffusion of oxygen, lead and Pt. In the case of Ta, there is little diffusion of $\mathrm{Ta}$ through the platinum electrode but lead and oxygen diffuse down to stabilize a PbTaO phase, which forms a regular layer. The $\mathrm{TiO}_{\mathrm{x}}$ adhesion layer is also different since it is already oxidized and relatively stable. In that case, during PZT deposition, diffused species are mainly present at the interfaces with $\mathrm{Pt}$ and $\mathrm{SiO}_{2}$ and in the $\mathrm{SiO}_{2}$ where it may form a lead silicate oxide.

The $\mathrm{Ti}$ adhesion layer is probably the worst since it is very irregular and a lot of diffusion is observed. Ta is probably relatively good concerning the mechanical stability. The observed layer is homogeneous and not much deformation of the platinum is present. However, it still corresponds to a high quantity of lead diffusion, which may correspond to presence of defects at the Pt-PZT interface. With the $\mathrm{TiO}_{\mathrm{x}}$ adhesion layer there is less diffusion but when this diffusion occurs, it is found at the interfaces, which may affect the mechanical stability of the device.

\section{ACKNOWLEDGMENTS}

This research was founded by the Swiss priority program on materials research and by the Swiss priority program on optics. The electron microscope work was performed at the CIME (EPFL). Finally we would like to thanks L. Gerard and D. Laub for help with the TEM sample preparation, and Dr. D. V. Taylor and Dr. A. Seifert for helpful discussions.

\section{REFERENCES}

I. M. Reaney, K. Brooks, R. Klissurka, C. Pawlaczyk, and N. Setter, J. American Ceram. Soc. 77, 1209-1216 (1994).

P. D. Hren, S. H. Rou, H. N. Al-Shareef, M. S. Ameen, O. Auciello, and A. I. Kingon, Integrated Ferroelectrics 2, 311-325 (1992).

C. Voisard, K. B. Brooks, I. M. Reaney, L. Sagalowicz, A. L. Kholkin, N. Xanthopoulos, and N. Setter, J. European Ceramic Society 17, 359-367 (1997).

S. G. Gap, K.-T. Shim, and Y.-H. Lee, Jpn. J. Appl. Phys. I 38, $217-218$ (1999).

T. Nakamura, Y. Nakao, A. Kamisawa, and H. Takasu, Jpn. J. Appl. Phys. 33, 5207-5210 (1994).

6 T. Maeder, P. Muralt, L. Sagalowicz, and N. Setter, Journal of the Electrochemical Society 146, 3393-3397 (1999).

7 E. Van Cappellen, Microsc. Microanal. Microstruct. 1, 1-22 (1990).

8 R. W. Whatmore, Z. Huang, and M. Todd, J. Appl. Phys. 82, 5686-5694 (1997).

9 T. Maeder, L. Sagalowicz, and P. Muralt, Jpn. J. Appl. Phys. 37, 2007-2012 (1998). 